\title{
Anemia prevalence, severity, types, and correlates among adult women and men in a multiethnic Iranian population: the Khuzestan Comprehensive Health Study (KCHS)
}

Elham Akbarpour ${ }^{1 \dagger}$, Yousef Paridar ${ }^{2 \dagger}$, Zahra Mohammadi ${ }^{1}$, Ali Mard ${ }^{3}$, Leila Danehchin ${ }^{4}$, Farhad Abolnezhadian ${ }^{5}$, Shima Azadpour ${ }^{6}$, Zahra Rahimi ${ }^{7}$, Mohammad Zamani $^{8}$, Bahman Cheraghian ${ }^{9}$, Hossein Poustchi $^{1 *}$ and Ali-Akbar Shayesteh ${ }^{10,11^{*}}$

\begin{abstract}
Background: Despite all recent health-related improvements, anemia remains an extensive global public health issue affecting the lives of about one-fourth of the world population in a geographically heterogeneous pattern. We, therefore, aimed to illustrate the prevalence, severity, most common types, and major determinants of anemia among adults in Khuzestan, Iran, from 2016 to 2019.

Methods: In a large population-based cross-sectional study comprising of a diverse population, each participant underwent a questionnaire-based interview and laboratory testing for hematological analysis. A hemoglobin (HGB) concentration of $<12 \mathrm{~g} / \mathrm{dL}$ in non-pregnant women and $<13 \mathrm{~g} / \mathrm{dL}$ in men were defined anemic. The multivariate logistic regression analysis was performed to explore the association between anemia and its potential determinants.

Results: Data on 29,550 (96.87\%) males and non-pregnant females between 20-65 years of age (mean age: $41.90 \pm 11.88$ years; female sex: 63.58\%; Arab ethnicity: 48.65\%), whose HGB level was available, were included in the study. The mean \pm SD HGB concentration was $13.75 \pm 1.65 \mathrm{~g} / \mathrm{dL}$. The age- and sex-standardized prevalence rate of anemia was 10.86\% (95\% Cl: 10.51-11.23\%). The most prevalent degree was mild anemia (7.71\%, 95\% Cl: 7.40-8.03\%) and only $0.17 \%$ were severely anemic. Of those considered anemic, the highest proportion was related to normochromic/microcytic (50.65\%), followed by hypochromic/microcytic (30.29\%).
\end{abstract}

\footnotetext{
*Correspondence: h.poustchi@gmail.com; shayestehaliakbar5@gmail.com

${ }^{\dagger}$ Elham Akbarpour and Yousef Paridar contributed equally to this work.

${ }^{1}$ Liver and Pancreatobiliary Diseases Research Center, Digestive Disease

Research Institute, Tehran University of Medical Sciences, Shariati Hospital,

N. Kargar St., 14117 Tehran, Iran

${ }^{10}$ Alimentary Tract Research Center, Imam Khomeini Hospital

Clinical Research Development Unit, Department of Biostatistics

and Epidemiology, School of Public Health, Ahvaz Jundishapur University

of Medical Sciences, Ahvaz, Iran

Full list of author information is available at the end of the article
}

(c) The Author(s) 2022. Open Access This article is licensed under a Creative Commons Attribution 4.0 International License, which permits use, sharing, adaptation, distribution and reproduction in any medium or format, as long as you give appropriate credit to the original author(s) and the source, provide a link to the Creative Commons licence, and indicate if changes were made. The images or other third party material in this article are included in the article's Creative Commons licence, unless indicated otherwise in a credit line to the material. If material is not included in the article's Creative Commons licence and your intended use is not permitted by statutory regulation or exceeds the permitted use, you will need to obtain permission directly from the copyright holder. To view a copy of this licence, visit http://creativecommons.org/licenses/by/4.0/. The Creative Commons Public Domain Dedication waiver (http://creativeco mmons.org/publicdomain/zero/1.0/) applies to the data made available in this article, unless otherwise stated in a credit line to the data. 
In the multiple logistic regression, the parameters of female gender (OR: 3.17,95\% Cl: 2.68-3.76), age group of 35-49 years (OR: 1.66, 95\% Cl: 1.52-1.82), being underweight (OR: 1.58, 95\% Cl: 1.29-1.93), being unemployed or retired (OR: 1.55, 95\% Cl: 1.33-1.81), and living in urban areas (OR: 1.18, 95\% Cl: 1.09-1.29) were major determinants of anemia. Additionally, we observed a minor but significant positive association between anemia status and CKD, older ages, increased night sleep duration, being a housewife and married, as well as a negative association between anemia and factors including hookah smoking, presence of metabolic syndrome, and overweight and obesity.

Conclusions: Taken together, the anemia prevalence in this study population was of mild public health significance. The major suspected causes might be iron deficiency and chronic disease anemias. Comparably higher rates of anemia were observed amongst women, individuals aged 35-49 years, underweights, unemployed or retired subjects, and urban residents.

Keywords: Anemia, Anemia severity, Anemia types, Population-based study, Public health, Epidemiology, Prevalence, Associated factors, Iran

\section{Background}

As defined by the World Health Organization (WHO), anemia is a condition in which the red blood cells (RBCs) count or the within hemoglobin (HGB) content falls below an established reference range $(<12 \mathrm{~g} / \mathrm{dL}$ in nonpregnant women and $<13 \mathrm{~g} / \mathrm{dL}$ in men), resulting in an impaired oxygen-carrying capacity to meet the tissues' physiological demands [1]. However, the optimal threshold for healthy individuals may vary due to personal and environmental conditions.

Anemia is regarded as the most prevailing micronutrient deficiency disorder worldwide, mainly in the poor socioeconomic strata of societies and as a result of poverty $[2,3]$. According to the estimates derived from the Global Burden of Diseases, Injuries and Risk Factors 2013 Study (GBD 2013), anemia affects the lives of nearly 1.93 billion people worldwide, corresponding to $27 \%$ of the global population [4]. The prevalence rate of anemia especially maximizes in low- and middle- income countries, and mostly among under- 5 children, pregnant and lactating women, and the elderly [3]. Although, there exists a slight downward trend from 1990 to 2010 in absolute prevalence and years lived with disability (YLD) caused by anemia, a great physical burden (61.5 million YLDs) and health-care cost (additional \$7,000-\$30,000 than the same condition without anemia) is still inflicted on the health systems $[3,5]$. Iran is an upper-middleincome country in the middle east, with an estimated age-standardized prevalence rate of $23 \%$ based on GBD 2013, [4] which is classified as moderate by WHO regarding the anemia prevalence [6]. The estimated anemia frequency in Iran varies between 10-30\%, specifically higher in children and adolescents, females, and older ages [7].

An intricate interplay of several concomitant factors (such as biological factors, demographics, lifestyle, personal habits, socioeconomic status, and geographical differences) may affect the distribution and severity, the pattern of the underlying pathophysiology, vulnerability to, and consequences of anemia $[8,9]$. Iron deficiency is the most common etiology of anemia and responsible for more than half of anemia cases worldwide [3]. The other possible contributors of anemia in low- and middle-income countries include the shortage of non-iron hematopoietic nutrients (folic acid, vitamin B12, and vitamin A), parasitic diseases and infections (malaria, hookworm infections, and schistosomiasis), inherited hemoglobinopathies (sickle cell disease and thalassemia), chronic diseases (cancer, autoimmune disease, chronic kidney disease, and congestive heart failure) [8].

Anemia can be troublesome both as being a sign of a serious underlying health condition, such as cancer, or by causing symptoms itself. Untreated anemia could cause low energy, strength, and productivity, presenting as chronic fatigue, lethargy, concentration difficulty, low blood pressure, shortness of breath, and even impaired mental well-being [10-13]. Despite all recent social and economic development and health-related improvements, anemia remains an extensive global public health issue affecting individuals at any stage of life from both developing and developed countries and causing serious impacts on quality of life, morbidity, and mortality [2].

Given the burden inflicted on the health system by anemia, it is crucial to modify the health-care policies in a way that enables some appropriate intervention measures against anemia. To our knowledge, of a sparse number of studies attempting to estimate the prevalence of anemia in Iran, most are restricted to children, adolescents, and women of childbearing age, whether pregnant or not, and such studies lack consistency and community representation [7, 14-16]. As stated in these studies, anemia has heterogeneous patterns geographically and across different populations in terms of epidemiological indicators, [7] so it is important to precisely identify their prevalence and region-specific contributors both at the national and regional levels to be able to implement a more relevant and efficient plan. Population-based cross-sectional 
studies serve as plausible evidence in this regard. Correspondingly, the Khuzestan Comprehensive Health Study (KCHS) was established between 2016 and 2019 to create the framework needed for priority setting in health policymaking and research [17]. As a part of the KCHS, we aimed to illustrate the overall and age- and sex-standardized prevalence, severity, most common types, and major associated risk factors of anemia among adult men and non-pregnant women at the provincial level in Khuzestan, Iran, from 2016 to 2019. This report is one of the most comprehensive extensive population-based studies of anemia in Iran.

\section{Methods}

\section{Design and setting}

In a descriptive analytics cross-sectional study, as a part of the KCHS study, we reported the overall and age- and sex-standardized prevalence, severity, most common types, and determinants of anemia among adult men and non-pregnant women at the provincial and county-level. The KCHS is a large population-based cross-sectional study comprising of about 30,000 Iranian adults from 27 counties of Khuzestan province, southwest of Iran, which aims to assess several health aspects, including the burden of NCDs, as well as identifying their contributors. This project was funded by the National Institute for Medical Research Development (NIMAD) (grant number: 940406) in partnership with Iranian Blood Transfer Organization (IBTO). It was first launched in October 2016 with the cooperation of Digestive Diseases Research Institute (DDRI), Jundishapur and Dezful universities of medical sciences, and Abadan and Behbahan faculties of medicine. The enrollment lasted up to November 2018. Details of the methods on data collection, protocols, and study design have already been presented elsewhere [17]. The investigators of the DDRI affiliated to Tehran University of Medical Sciences (TUMS), Tehran, Iran, prepared this report in October 2020. The KCHS protocol was approved by the ethics committees of the NIMAD (IR. NIMAD.REC.1394.002), and was conducted in accordance with the Declaration of Helsinki. All participants have authorized using the recorded data for scientific goals.

\section{Study population, and sample size}

Khuzestan is a southwestern province of Iran, bordering Iraq and the Persian Gulf, with near 5 million estimated inhabitants of various ethnicities, cultures, lifestyles, and socioeconomic groups from 27 counties. The climate is generally hot semi-arid or desert, and it is covered by two different landforms, mountainous in the north and flat in the south. This province of Iran has been geopolitically exposing to numerous health threats, such as war, air pollution, oil resources, dust phenomena, and extreme high temperatures. The KCHS was based on about $0.6 \%$ of this population from all 27 distinct counties of Khuzestan. Overall, 30,506 male and female adults between 20-65 years of age from both urban and rural regions were included to the KCHS. No exclusion criteria, other than an unwillingness to participate in the study or having mental or physical disabilities confounding the completion of questioning process, were used. In a stratified random sampling approach, a number of Health Houses (primary care centers) in each of the 27 counties were selected based on the proportion of the total province population living in that county. Thereafter, 30 random individuals who fulfilled the eligibility criteria were recruited from the population census at each Health House. The estimated sample size is large enough to specify the prevalence of anemia in this region.

\section{Data collection, variables, and measurements}

The data collection process of the KCHS is summarized as follows: Based on a stratified random multistage sampling plan, the target participants were selected and visited face-to-face by a trained staff member. After providing an adequate explanation about the aim of research to the subjects, they were invited to the study sites if they agreed to participate. On the morning of the visit day, a written informed consent was obtained initially. Firstly, venous blood samples were taken from each subject after 8 to $12 \mathrm{~h}$ of fasting, and then, anthropometric indices and blood pressure were measured. The samples were refrigerated in cool boxes, shipped to the reference laboratory within three hours, and analyzed for hematological and biochemical parameters. Finally, each individual was interviewed and a standardized questionnaire regarding general, medical condition, was completed for all participants (Additional file 2). Additionally, nutritional information, as well as, few other specific conditions (such as gastrointestinal and psychological variables), were recorded for a subsample. A quality assurance and quality control team was assembled to regularly review the data collection procedures.

All required data for this report were extracted from the database of the KCHS and are outlined in Additional file 1 by the definitions and categories of each variable.

The anemia status applied in our report was accorded with the WHO definition of anemia, [1] i.e. a HGB concentration of $<12 \mathrm{~g} / \mathrm{dL}$ in non-pregnant women and $<13 \mathrm{~g} / \mathrm{dL}$ in men. In addition, the anemia severity was categorized into three groups of mild (HGB: $11-11.9 \mathrm{~g} / \mathrm{dL}$ in women and $11-12.9 \mathrm{~g} / \mathrm{dL}$ in men), moderate (HGB: $8-10.9 \mathrm{~g} / \mathrm{dL}$ ), and severe anemia $(\mathrm{HGB}<8 \mathrm{~g} / \mathrm{dL})$. The anemia type was classified by the following hematimetric indices (Additional file 1): Mean 
Corpuscular Hemoglobin Concentration (MCHC); Mean Corpuscular Volume (MCV) [11].

In this study, the primary outcome was to assess the crude and age- and sex-standardized prevalence rate of anemia among adult men and non-pregnant women population of Khuzestan. Secondly, the respective figures were specifically explored to determine the potential associated factors. Finally, we studied the characteristics of anemia, like the distribution of anemia severity and major clinical types of anemia, in age-specific subgroups by gender.

\section{Statistical analysis}

The database was first structured using Microsoft Office Excel 2016 and all statistical analyses were conducted using Stata/SE version 12 (StataCorp, Texas, USA). The graphs were created using Microsoft Office Excel 2016. Additionally, ArcGIS version 10.8 was used to generate the county-level age- and sex-standardized prevalence rates in the study area map. Frequency, percentage, and 95\% Confidence Interval (95\% CI) were used as descriptive statistics for categorical variables to summarize the characteristics of the anemic study population. Moreover, we estimated age- and sex-standardized prevalence rates of anemia using the age and sex structure of the Khuzestan population census the year 2015. We visualized the distribution of the anemia status among men and women by age. Anemia prevalence (crude and ageand sex-standardized) rates were reported as proportions along with $95 \%$ CI for various subgroups. For comparison between these groups of explanatory variables by anemia levels, the chi-squared test was performed to explore unadjusted associations. The severity and different types of anemia were compared between gender and age groups, as well. The crude association between anemia and its potential determinants was assessed using the univariate logistic regression analysis. Explanatory variables that were found to have a significant association with anemia in the univariate analysis, were further adjusted through multivariable logistic regression models using a forward stepwise approach. The Odds Ratios (ORs) and their 95\% CI were calculated by logistic regression analysis to measure the strength of the association. The goodness of fit of the final model was checked by Hosmer-Lameshow test, at $p$-value of $>0.05$. A twosided $p$-value below 0.05 was considered statistically significant.

\section{Results}

\section{Inclusion and general characteristics}

Out of 30,506 individuals aged between 20 and 65 years old primarily registered in the $\mathrm{KCHS}$ through October 2016 to November 2018, 437 (1.43\%) participants for whom a HGB measurements were not available, and 519 $(1.70 \%)$ pregnant women were excluded. Data on 29,550 (96.87\%) participants were included in the final analysis.

The mean \pm SD age of the study population was $41.90 \pm 11.88$ years, and a female to male ratio of $1.75: 1$ was present. The distribution of subjects among different age groups was almost the same, with a slightly larger proportion in the middle age group of 35-49 years (38.77\%). About three-quarters of participants were urban residents (73.54\%), and others were from rural areas (26.46\%). Arab ethnicity accounted for nearly half of the participants (48.65\%), followed by Bakhtiari (22.06\%), and Fars (18.68\%) ethnicity. The majority of participants were married (82.71\%). Regarding educational status, more than two-third of the study participants had primary $(n=8,899,30.12 \%)$ or secondary $(n=11,445,38.73 \%)$ levels of education, 5,441 (18.41\%) were illiterate, and only 3,761 (12.73\%) had university degrees and above. Only 8,731 (29.55\%) subjects had an independent source of income, whether governmental, private, or self-employed, and 17,195 (58.19\%) were housewives. In terms of wealth, individuals equally belonged to different quantiles from poorest to richest. Overall, more than two-third of individuals suffered from overweight $(n=11,064,37.44 \%)$ or obesity $(n=8,814,29.83 \%)$, and to some degree, 17,947 (60.73\%) had an increased abdominal obesity. Currently or past, $3,253(11.01 \%)$ and $1,582(5.35 \%)$ of participants had ever smoked cigarettes and hookah in their lifetime, respectively, whereas, $641(2.17 \%)$ had consumed alcohol, and 834 (2.82\%) had used opium. Among all participants, the duration of night sleep was not enough or excessive in 12,994 (43.92\%) subjects, and the amount of physical activity was classified as low, moderate, and high in 9,173 (31.04\%), 12,597 (42.63\%), and 7,703 (26.07\%), respectively. Diabetes, hypertension, metabolic syndrome, and Chronic Kidney Disease (CKD) were present in 4,597 (15.56\%), 5,883 (19.91\%), 9,652 (32.66\%), and 2,115 (7.2\%) of the study population, respectively.

\section{Prevalence, severity, and types of anemia}

The mean \pm SD HGB concentration of the study population was $13.75 \pm 1.65 \mathrm{~g} / \mathrm{dL}$, and as expected, it was significantly lower in women than in men $(12.94 \pm 1.24$ versus $15.15 \pm 1.32, p$-value $<0.0001)$. Using WHO cut-off values, $25,651(86.8 \%)$ individuals were non-anemic $(24,323$ [82.3\%] with normal HGB levels and 1,328 [4.5\%] with polyglobulinemia) and 3,899 participants were found to be anemic. Thus, the overall and age- and sex-standardized prevalence rates of anemia were $13.19 \%(95 \%$ CI: $12.81-13.59 \%)$ and $10.86 \%$ (95\% CI: 10.51-11.23\%), respectively (Fig. 1). 


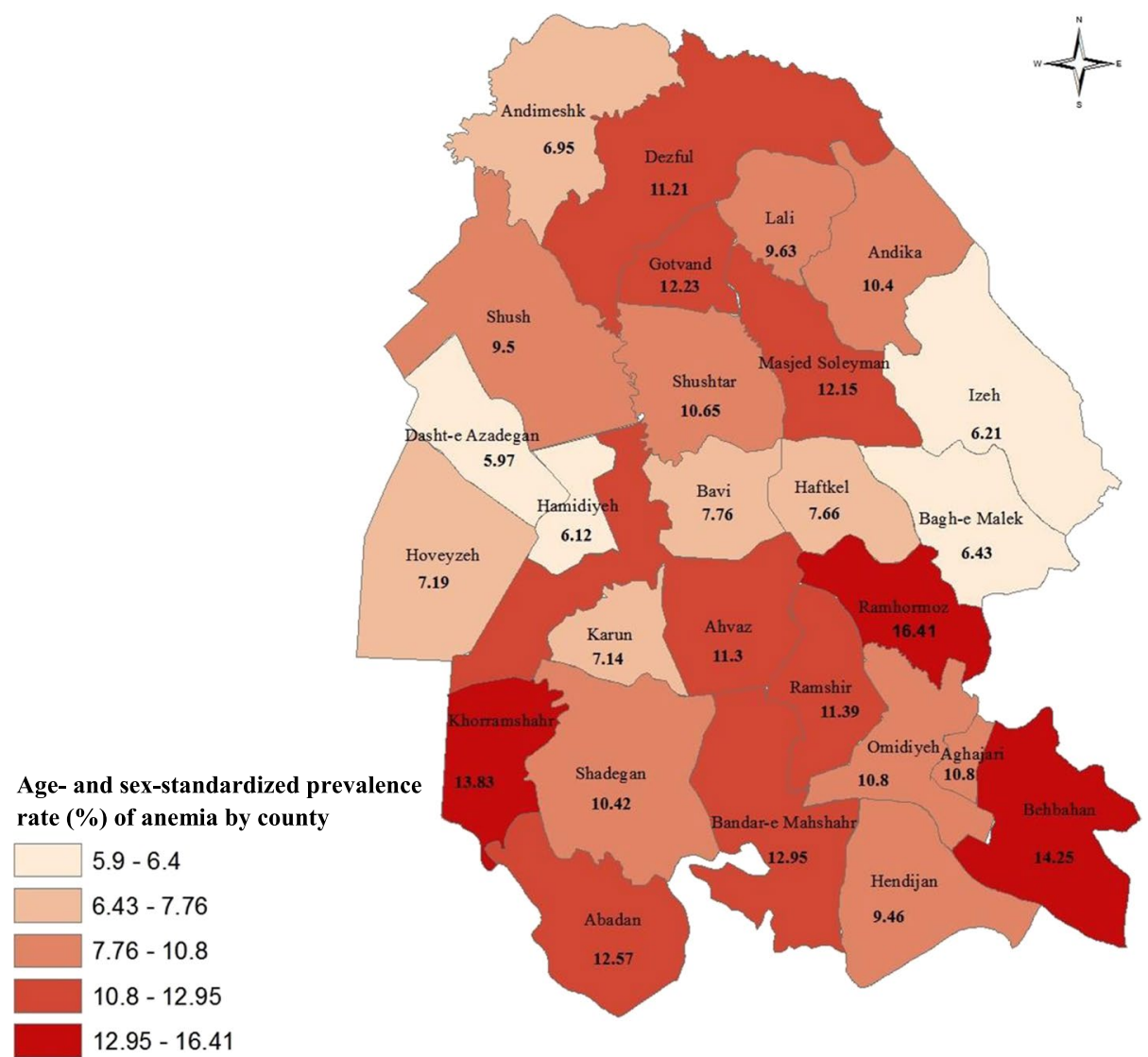

Fig. 1 Visualizes the county-level age- and sex-standardized prevalence rate of anemia in the study population. There exists a wide regional variation of anemia level in Khuzestan, ranging from 5.97\% in Dashte-e Azadegan to $16.41 \%$ in Ramhormoz

Khuzestan map showing the county-level age- and sexstandardized prevalence rate of anemia in the study population, from 2016 to 2019.

As shown in Fig. 2, important gender differences were observed in the prevalence of anemia. The anemia prevalence was notably higher among women compared to men in all age groups (adjusted: $17.08 \%$ versus $4.87 \%$, $p$-value $<0.0001)$. However, the lines converge in older ages, as the prevalence rises in males and falls in females after middle-ages. In women, the anemia prevalence peaked in the 45-49 years, whereas the youngest subjects of 20-24-year group displayed comparably low rates ( $23.39 \%$ versus $12.88 \%, p$-value $<0.0001)$. On the other hand, men experienced a steadily increasing trend in anemia prevalence with increasing age.

Mild degree anemia accounted for most of the cases with an age- and sex-standardized prevalence rate of 7.71\% (95\% CI: $7.40-8.03 \%$ ), followed by moderate anemia in $2.98 \%$ (95\% CI: $2.80-3.17 \%)$. Severe anemia was rare, with only $73(0.17 \%, 95 \%$ CI: $0.14-0.22 \%)$ cases. Table 1 shows the age-specific proportion of anemia severity by gender. Of the anemic female population, a higher proportion suffered from moderate and severe anemia compared to the anemic men $(34.82 \%$ versus $10.31 \%)$. The proportion of moderate and severe anemia was higher in the age group of $35-49$ years $(38.15 \%)$ compared with other age groups. Almost the same proportion was observed in females of $35-49$ years $(38.15 \%)$, but there was no significant age-specific difference in anemia severity among men.

The types of anemia in age-specific subgroups by gender among the anemic population are presented in Table 2. According to the classification of anemias regarding the $\mathrm{MCV}$ and $\mathrm{MCHC}$ values, of those considered anemic, the highest proportion was related to normochromic/microcytic (50.65\%), followed by hypochromic/microcytic (30.29\%) and normochromic/ normocytic (16.36\%) anemia.

\section{Factors associated with anemia}

The crude and age- and sex-standardized prevalence rates of anemia by baseline characteristics are shown in 


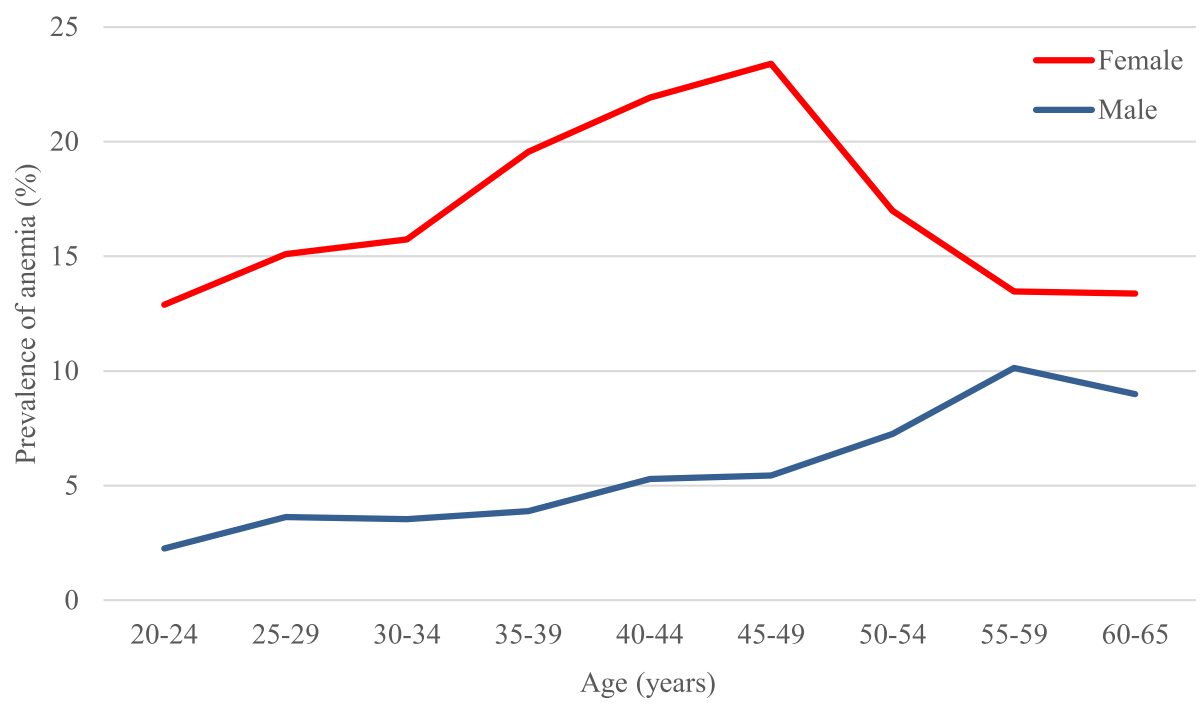

Fig. 2 Line graphs illustrating the prevalence of anemia among females and males by age, Khuzestan, Iran, from 2016 to 2019

Table 1 The severity of anemia in age-specific subgroups by gender among anemic population $(n=3,899)$ in Khuzestan, Iran, from 2016 to 2019

\begin{tabular}{|c|c|c|c|c|}
\hline \multirow[t]{2}{*}{ Variables } & \multicolumn{3}{|c|}{ Anemia severity $^{a}$} & \multirow[t]{2}{*}{$P$-value * } \\
\hline & Mild & Moderate & Severe & \\
\hline Overall & $\begin{array}{l}2,691 \\
(69.02 \%)\end{array}$ & $\begin{array}{l}1,135 \\
(29.11 \%)\end{array}$ & $73(1.87 \%)$ & \\
\hline \multicolumn{5}{|l|}{ Total } \\
\hline $\begin{array}{l}\text { Age groups } \\
\text { (years) }\end{array}$ & & & & $<0.0001$ \\
\hline $20-34$ & $710(70.44 \%)$ & 288 (28.57\%) & 10 (0.99\%) & \\
\hline $35-49$ & $1,170(64.82 \%)$ & $585(32.41 \%)$ & $50(2.77 \%)$ & \\
\hline $50-65$ & $809(74.98 \%)$ & $257(23.82 \%)$ & $13(1.2 \%)$ & \\
\hline Gender & & & & $<0.0001$ \\
\hline Female & $2,143(65.18 \%)$ & 1,075 (32.69\%) & 70 (2.13\%) & \\
\hline Male & 548 (89.69\%) & $60(9.82 \%)$ & $3(0.49 \%)$ & \\
\hline \multicolumn{5}{|l|}{ Female } \\
\hline $20-34$ & $615(68.41 \%)$ & 274 (30.48\%) & $10(1.11 \%)$ & $<0.0001$ \\
\hline $35-49$ & 997 (61.85\%) & $566(35.11 \%)$ & 49 (3.04\%) & \\
\hline $50-65$ & $529(68.43 \%)$ & $233(30.14 \%)$ & $11(1.42 \%)$ & \\
\hline \multicolumn{5}{|l|}{ Male } \\
\hline 20-34 & $95(87.16 \%)$ & $14(12.84 \%)$ & 0 & 0.544 \\
\hline $35-49$ & $173(89.64 \%)$ & $19(9.84 \%)$ & $1(0.52 \%)$ & \\
\hline $50-65$ & 280 (91.5\%) & $24(7.84 \%)$ & $2(0.65 \%)$ & \\
\hline
\end{tabular}

Notes: *The chi-squared test was performed for comparison between the groups. Significance level was at $p$-value $<0.05$

${ }^{a}$, mild anemia: hemoglobin 11-11.9 g/dL in women and $11-12.9 \mathrm{~g} / \mathrm{dL}$ in men; moderate anemia: hemoglobin $8-10.9 \mathrm{~g} / \mathrm{dL}$; severe anemia: hemoglobin $<8 \mathrm{~g} /$ $\mathrm{dL}$ detail in Table 3. The univariate analysis demonstrated that 17 variables were significantly associated with the age- and sex-standardized anemia status. Accordingly, anemia was significantly more prevalent among female sex, individuals aged 35-49 years, urban residents, Fars ethnicity, divorced or widowed category, illiterate educational levels, housewives, lower wealth status, underweight subjects, excessive night sleepers, those with moderate physical activity, and participants with CKD. Moreover, cigarettes or hookah smokers, opium users, alcohol drinkers, and participants with metabolic syndrome were negatively associated with anemia. There were no significant differences in relation to the other variables of the study.

A multiple logistic regression was performed to ascertain whether the explanatory variables found in univariate analyses could be further confirmed. As shown in Table 4, eleven associations for anemia were highlighted in the multivariable analysis: 1. gender, 2 . age groups, 3 . Body Mass Index (BMI) category, 4. occupation, 5. area of residence, 6. hookah smoking, 7. presence of CKD, 8. presence of metabolic syndrome, 9. night sleep duration, 10. marital status, and 11. ethnicity. The Nagelkerke pseudo-R2 for the model was 0.074 and the $p$-value for Hosmer-Lemeshow test was 0.107. In this analysis, gender, age groups, BMI category, occupation, and area of residence, were able to explain $7.0 \%$ of the variability in anemia status compared to $7.4 \%$ in the saturated model.

In the final model of logistic regression, the odds of anemia were more than threefold (OR: 3.17, 95\% CI: 2.68-3.76) increased with women than men. Age was found to be significantly related to anemia with odds ratio of 1.66 (95\% CI: $1.52-1.82)$ in the age group 
Table 2 The types of anemia in age-specific subgroups by gender based on the mean corpuscular volume and mean corpuscular hemoglobin concentration among anemic population $(n=3,899)$ in Khuzestan, Iran, from 2016 to 2019

\begin{tabular}{|c|c|c|c|c|c|}
\hline \multirow[t]{2}{*}{ Variables } & \multicolumn{4}{|l|}{ Anemia type } & \multirow[t]{2}{*}{$P$-value * } \\
\hline & $\begin{array}{l}\text { Normochromic } \\
\text { Normocytic }\end{array}$ & Normochromic Microcytic & Hypochromic Microcytic & Others $^{a}$ & \\
\hline Overall & $638(16.36 \%)$ & $1,975(50.65 \%)$ & $1,181(30.29 \%)$ & $105(2.69 \%)$ & \\
\hline \multicolumn{6}{|l|}{ Total } \\
\hline Age groups (years) & & & & & $<0.0001$ \\
\hline $20-34$ & $155(15.38 \%)$ & $530(52.58 \%)$ & $296(29.37 \%)$ & $27(2.68 \%)$ & \\
\hline $35-49$ & $255(14.13 \%)$ & $962(53.3 \%)$ & $552(30.58 \%)$ & $36(1.99 \%)$ & \\
\hline $50-65$ & $227(21.04 \%)$ & $481(44.58 \%)$ & $331(30.68 \%)$ & $40(3.71 \%)$ & \\
\hline Gender & & & & & $<0.0001$ \\
\hline Female & $526(16.00 \%)$ & $1,724(52.43 \%)$ & 956 (29.08\%) & $82(2.49 \%)$ & \\
\hline Male & $112(18.33 \%)$ & $251(41.08 \%)$ & $225(36.82 \%)$ & $23(3.76 \%)$ & \\
\hline \multicolumn{6}{|l|}{ Female } \\
\hline $20-34$ & $145(16.13 \%)$ & $492(54.73 \%)$ & $238(26.47 \%)$ & $24(2.67 \%)$ & 0.001 \\
\hline $35-49$ & $227(14.08 \%)$ & $874(54.22 \%)$ & $477(29.59 \%)$ & $34(2.11 \%)$ & \\
\hline $50-65$ & $153(19.79 \%)$ & $357(46.18 \%)$ & $240(31.05 \%)$ & $23(2.98 \%)$ & \\
\hline \multicolumn{6}{|l|}{ Male } \\
\hline $20-34$ & $10(9.17 \%)$ & $38(34.86 \%)$ & $58(53.21 \%)$ & $3(2.75 \%)$ & $<0.0001$ \\
\hline $35-49$ & $28(14.51 \%)$ & $88(45.6 \%)$ & 75 (38.86\%) & $2(1.04 \%)$ & \\
\hline $50-65$ & $74(24.18 \%)$ & $124(40.52 \%)$ & 91 (29.74\%) & $17(5.56 \%)$ & \\
\hline
\end{tabular}

Notes: *The chi-squared test was performed for comparison between the groups. Significance level was at $p$-value $<0.05$

a , Other types include: hypochromic/normocytic: 25 (0.64\%); hyperchromic/microcytic: 49 (1.26\%); hyperchromic/normocytic: 28 (0.72\%); and hyperchromic macrocytic: $3(0.08 \%)$

35-49 years, and 1.27 (95\% CI: $1.14-1.42)$ in the age group 50-65 years as compared with age group 20-34 years. Compared to normal BMI, individuals who were underweight were 1.58 times (95\% CI: 1.29-1.93) as likely to have anemia. Regarding occupation, being unemployed or retired (OR: 1.55, 95\% CI: 1.33-1.81), followed by being housewife (OR: 1.26, 95\% CI: 1.07-1.48) was associated with higher prevalence of anemia than those who were working. And finally, there was a tendency for higher anemia prevalence in subjects living in urban areas than in rural areas (OR: 1.18, 95\% CI: $1.09-1.29)$. Those suffering from CKD (OR: 1.27, 95\% CI: 1.12-1.44), excessive night sleepers versus normal sleepers (OR: 1.19, 95\% CI: 1.06-1.35), and married participants versus singles (OR: 1.16, 95\% CI: $1.02-1.32$ ) had only slightly increased likelihood of anemia. The observed negatively associated factors for anemia were hookah smoking (OR: 0.67, 95\% CI: 0.53-0.83), metabolic syndrome (OR: 0.87 , 95\% CI: $0.80-0.95$ ), overweight and obesity (OR: $0.80,95 \% \mathrm{CI}$ : $0.73-0.87$, and OR: $0.84,95 \%$ CI: $0.76-0.93$, respectively), and belonging to minority ethnic groups (OR: 0.83, 95\% CI: $0.72-0.95 \%)$. There was no difference between other remaining variables.

\section{Discussion}

Anemia is a major global public health problem affecting about one-quarter of the world's population [4]. The available data from the previous epidemiological studies indicate that the anemia status varies among populations depending on various factors. Therefore, we aimed at addressing the provincial and county-level prevalence of anemia, its severity and types in a large population-based study representative of the general adult population in Khuzestan province, as well as thoroughly investigating its association with the background characteristics of subjects.

\section{Anemia status (prevalence, severity, and subtypes) and associated factors}

The prevalence of anemia among men and non-pregnant women aged between 20-65 years in Khuzestan was $10.86 \%$, which is categorized of mild public health significance as per WHO classification and it is similar to high-income countries [1]. The most prevalent degree of anemia was mild (7.71\%), followed by moderate $(2.98 \%)$, and only $0.17 \%$ of all subjects were severely anemic. Our findings are in line with the results of the second national 
Table 3 The crude and age- and sex-standardized prevalence rates of anemia by baseline characteristics $(n=3,899)$ in Khuzestan, Iran, from 2016 to 2019

\begin{tabular}{|c|c|c|c|c|}
\hline \multirow[t]{2}{*}{ Variables } & \multirow[t]{2}{*}{ Frequency (n) } & \multicolumn{2}{|c|}{ Anemia prevalence $\%(95 \% \mathrm{Cl})$} & \multirow[t]{2}{*}{$P$-value ${ }^{*}$} \\
\hline & & Crude & Age- and sex-standardized & \\
\hline Overall & $3,899 / 29,550$ & $13.19(12.81-13.59)$ & $10.86(10.51-11.23)$ & \\
\hline \multicolumn{5}{|l|}{ Demographics } \\
\hline Gender ** & & & & $<0.0001$ \\
\hline Female & $3,288 / 18,789$ & $17.50(16.96-18.05)$ & $17.08(16.52-17.66)$ & \\
\hline Male & $611 / 10,761$ & $5.68(5.26-6.13)$ & $4.87(4.47-5.30)$ & \\
\hline Age categories (years) ${ }^{a * *}$ & & & & $<0.0001$ \\
\hline $20-34$ & $1,008 / 9,329$ & $10.81(10.19-11.45)$ & $9.19(8.64-9.76)$ & \\
\hline $35-49$ & $1,805 / 11,456$ & $15.76(15.10-16.43)$ & $13.43(12.84-14.04)$ & \\
\hline $50-65$ & $1,079 / 8,711$ & $12.39(11.71-13.10)$ & $11.53(10.87-12.23)$ & \\
\hline Area of residence & & & & $<0.0001$ \\
\hline Rural & $900 / 7,819$ & $11.51(10.82-12.24)$ & $9.19(8.58-9.85)$ & \\
\hline Urban & $2,999 / 21,731$ & $13.80(13.35-14.27)$ & $11.54(11.12-11.98)$ & \\
\hline Ethnicity $^{a}$ & & & & 0.028 \\
\hline Arab & $1,902 / 14,377$ & $13.23(12.69-13.79)$ & $10.66(10.16-11.17)$ & \\
\hline Bakhtiari & $844 / 6,520$ & $12.94(12.15-13.78)$ & $10.75(10.01-11.54)$ & \\
\hline Fars & $766 / 5,521$ & $13.87(12.99-14.81)$ & $11.98(11.11-12.90)$ & \\
\hline Others & $380 / 3,078$ & $12.35(11.23-13.56)$ & $10.12(9.10-11.24)$ & \\
\hline Marital status & & & & $<0.0001$ \\
\hline Single & $404 / 3,601$ & $11.22(10.23-12.29)$ & $8.54(7.71-9.45)$ & \\
\hline Married & $3,257 / 24,441$ & $13.33(12.91-13.76)$ & $11.20(10.81-11.61)$ & \\
\hline Divorced / Widowed & $238 / 1,508$ & $15.78(14.03-17.71)$ & $15.41(13.59-17.43)$ & \\
\hline \multicolumn{5}{|l|}{ Socioeconomics variables } \\
\hline Educational Level ${ }^{\mathrm{b}}$ & & & & $<0.0001$ \\
\hline Illiterate & $805 / 5,441$ & $14.80(13.88-15.76)$ & $13.50(12.60-14.46)$ & \\
\hline Primary & $1,269 / 8,899$ & $14.26(13.55-15.00)$ & $12.22(11.55-12.92)$ & \\
\hline Secondary & $1,413 / 11,445$ & $12.35(11.76-12.96)$ & $10.02(9.48-10.58)$ & \\
\hline Tertiary & $411 / 3,761$ & $10.93(9.97-11.97)$ & $8.88(8.02-9.82)$ & \\
\hline Occupational status ${ }^{c}$ & & & & $<0.0001$ \\
\hline Working & $530 / 8,731$ & $6.07(5.59-6.59)$ & $5.08(4.63-5.56)$ & \\
\hline Housewife & $3,018 / 17,195$ & $17.55(16.99-18.13)$ & $17.10(16.52-17.71)$ & \\
\hline Unemployed / Retired / Student & $315 / 3,426$ & $9.19(8.27-10.21)$ & $7.68(6.83-8.64)$ & \\
\hline Wealth status quartiles ${ }^{d}$ & & & & 0.001 \\
\hline Lowest & $1,010 / 7,350$ & $13.74(12.97-14.55)$ & $11.58(10.85-12.35)$ & \\
\hline Up to median & $988 / 7,257$ & $13.61(12.84-14.42)$ & $11.65(10.91-12.44)$ & \\
\hline Above median & $1,014 / 7,843$ & $12.93(12.20-13.69)$ & $10.25(9.61-10.93)$ & \\
\hline Highest & $865 / 6,925$ & $12.49(11.73-13.29)$ & $10.06(9.37-10.79)$ & \\
\hline \multicolumn{5}{|l|}{ Individual factors } \\
\hline BMI categories ${ }^{e}$ & & & & $<0.0001$ \\
\hline Underweight & $139 / 811$ & $17.14(14.70-19.89)$ & $13.84(11.65-16.37)$ & \\
\hline Normal weight & $1,146 / 8,724$ & $13.14(12.44-13.86)$ & $10.71(10.08-11.38)$ & \\
\hline Overweight & $1,319 / 11,064$ & $11.92(11.33-12.54)$ & $9.71(9.17-10.28)$ & \\
\hline Obese & $1,271 / 8,814$ & $14.42(13.70-15.17)$ & $12.23(11.56-12.94)$ & \\
\hline Abdominal obesity ${ }^{f}$ & & & & 0.226 \\
\hline Normal & $1,545 / 11,463$ & $13.48(12.87-14.12)$ & $10.62(10.07-11.19)$ & \\
\hline Increased & $2,332 / 17,947$ & $12.99(12.51-13.49)$ & $11.06(10.60-11.53)$ & \\
\hline Ever cigarettes smoker ${ }^{9}$ & & & & $<0.0001$ \\
\hline Yes & $223 / 3,253$ & $6.86(6.04-7.78)$ & $5.40(4.68-6.22)$ & \\
\hline
\end{tabular}


Table 3 (continued)

\begin{tabular}{|c|c|c|c|c|}
\hline \multirow[t]{2}{*}{ Variables } & \multirow[t]{2}{*}{ Frequency (n) } & \multicolumn{2}{|c|}{ Anemia prevalence $\%(95 \% \mathrm{Cl})$} & \multirow[t]{2}{*}{$P$-value ${ }^{*}$} \\
\hline & & Crude & Age- and sex- standardized & \\
\hline No & $3,672 / 26,241$ & $13.99(13.58-14.42)$ & $11.75(11.36-12.15)$ & \\
\hline Ever hookah smoker ${ }^{g}$ & & & & $<0.0001$ \\
\hline Yes & $91 / 1,582$ & $5.75(4.71-7.01)$ & $3.80(3.03-4.76)$ & \\
\hline No & $3,804 / 27,912$ & $13.63(13.23-14.04)$ & $11.51(11.13-11.89)$ & \\
\hline Ever opium user ${ }^{g}$ & & & & $<0.0001$ \\
\hline Yes & $60 / 834$ & $7.19(5.63-9.16)$ & $5.58(4.28-7.24)$ & \\
\hline No & $3,835 / 28,660$ & 13.38 (12.99-13.78) & $11.07(10.71-11.45)$ & \\
\hline Ever alcohol drinker ${ }^{g}$ & & & & $<0.0001$ \\
\hline Yes & $22 / 641$ & $3.43(2.27-5.16)$ & $2.35(1.52-3.64)$ & \\
\hline No & $3,873 / 28,853$ & $13.42(13.03-13.82)$ & $11.20(10.83-11.57)$ & \\
\hline Sleeping duration ${ }^{h}$ & & & & $<0.0001$ \\
\hline Enough & $2,174 / 16,522$ & $13.16(12.65-13.68)$ & $10.85(10.38-11.34)$ & \\
\hline Not enough & $1,325 / 10,551$ & $12.56(11.94-13.20)$ & $10.14(9.58-10.74)$ & \\
\hline Excessive & $397 / 2,443$ & $16.25(14.84-17.77)$ & $13.79(12.46-15.24)$ & \\
\hline Physical activity tertiles ${ }^{i}$ & & & & $<0.0001$ \\
\hline Low & $1,080 / 9,173$ & $11.77(11.13-12.45)$ & $9.58(8.99-10.21)$ & \\
\hline Moderate & 1,779 / 12,597 & $14.12(13.53-14.74)$ & $12.08(11.51-12.68)$ & \\
\hline High & $1,032 / 7,703$ & $13.40(12.65-14.18)$ & $10.64(9.98-11.35)$ & \\
\hline \multicolumn{5}{|l|}{ Medical characteristics } \\
\hline Diabetes & & & & 0.128 \\
\hline Yes & $616 / 4,597$ & $13.40(12.45-14.42)$ & $11.64(10.74-12.61)$ & \\
\hline No & $3,283 / 24,953$ & $13.16(12.74-13.58)$ & $10.76(10.38-11.16)$ & \\
\hline Hypertension & & & & 0.193 \\
\hline Yes & $789 / 5,883$ & $13.41(12.56-14.31)$ & $11.42(10.62-12.27)$ & \\
\hline No & $3,110 / 23,667$ & $13.14(12.72-13.58)$ & $10.76(10.37-11.17)$ & \\
\hline Metabolic syndrome & & & & $<0.0001$ \\
\hline Yes & $1165 / 9,652$ & $12.07(11.44-12.74)$ & $9.83(9.25-10.43)$ & \\
\hline No & $2,734 / 19,898$ & $13.74(13.27-14.23)$ & $11.26(10.83-11.72)$ & \\
\hline $\mathrm{CKD}^{j}$ & & & & $<0.0001$ \\
\hline Yes & $270 / 2,115$ & 16.41 (14.89-18.05) & $14.51(13.06-16.10)$ & \\
\hline Non-CKD / Unknown & $3,622 / 27,376$ & $12.95(12.56-13.35)$ & $10.66(10.30-11.04)$ & \\
\hline
\end{tabular}

Abbreviations: $\mathrm{Cl}$ confidence interval, $\mathrm{BMI}$ body mass index, $C K D$ chronic kidney disease

Notes: *The chi-squared test was performed for comparison between the groups. Significance level was at $p$-value $<0.05$

${ }^{* *}$ Age-standardized

*** Sex-standardized

Missing values, count (\%): a, 54 (0.18); b, 4 (0.01); c, 198 (0.67); d, 175 (0.59); e, 137 (0.46); f, $140(0.47) ; g, 56(0.19) ;$ h, 34 (0.12); i, 77 (0.26); j, 59 (0.20ege)

integrated micronutrient survey in Iran, which estimated that the anemia prevalence is $10.3 \%(9.6-11.0 \%)$ among adults $45-60$ years [18]. In another a population-based cross-sectional study of 1,675 individuals aged 1-90 years in Mashhad, the prevalence of anemia was calculated to be $9.7 \%[19,20]$.

Normochromic/microcytic followed by hypochromic/ microcytic and normochromic/normocytic anemias in our study could point towards the fact that malnutrition, iron deficiency, thalassemia and chronic diseases are relevant causes for anemia in Khuzestan population
[21]. About four fifth of anemic subjects had microcytosis in both women and men, but among them, men had higher proportion of hypochromia compared to women (36.82\% versus $29.08 \%$ ). The proportion of normochromic/normocytic anemia increased with age in both males and females, which is mostly related to anemia of chronic disease [21]. Similarly, these types of anemia were also reported as the most prevalent types of anemia in various studies [22-24].

Either as a risk or consequence of anemia, the parameters of female gender, age group of 35-49 years, 
Table 4 Associated factors of the anemia prevalence in multivariable analysis in Khuzestan, Iran, from 2016 to 2019

\begin{tabular}{|c|c|c|c|}
\hline \multirow[t]{2}{*}{ Variables } & \multicolumn{2}{|c|}{ Anemia prevalence ratio ${ }^{a}$} & \multirow[t]{2}{*}{$P$-value ${ }^{*}$} \\
\hline & Adjusted $\mathrm{OR}^{\mathrm{b}}$ & $95 \% \mathrm{Cl}$ & \\
\hline \multicolumn{4}{|l|}{ Demographics } \\
\hline \multicolumn{4}{|l|}{ Gender } \\
\hline Female & 3.17 & $2.68-3.76$ & $<0.0001$ \\
\hline Male & Reference & & \\
\hline \multicolumn{4}{|l|}{ Age categories (years) } \\
\hline $20-34$ & Reference & & \\
\hline $35-49$ & 1.66 & $1.52-1.82$ & $<0.0001$ \\
\hline $50-65$ & 1.27 & $1.14-1.42$ & $<0.0001$ \\
\hline \multicolumn{4}{|l|}{ Area of residence } \\
\hline Rural & Reference & & \\
\hline Urban & 1.18 & $1.09-1.29$ & $<0.0001$ \\
\hline \multicolumn{4}{|l|}{ Ethnicity } \\
\hline Arab & 0.95 & $0.87-1.05$ & 0.334 \\
\hline Bakhtiari & 0.91 & $0.81-1.01$ & 0.081 \\
\hline Fars & Reference & & \\
\hline Others & 0.83 & $0.72-0.95$ & 0.008 \\
\hline \multicolumn{4}{|l|}{ Marital status } \\
\hline Single & Reference & & \\
\hline Married & 1.16 & $1.02-1.32$ & 0.021 \\
\hline Divorced / Widowed & 1.02 & $0.84-1.24$ & 0.844 \\
\hline \multicolumn{4}{|l|}{ Socioeconomics variables } \\
\hline \multicolumn{4}{|l|}{ Occupational status } \\
\hline Working & Reference & & \\
\hline Housewife & 1.26 & $1.07-1.48$ & 0.006 \\
\hline Unemployed / Retired / Student & 1.55 & $1.33-1.81$ & $<0.0001$ \\
\hline \multicolumn{4}{|l|}{ Individual factors } \\
\hline \multicolumn{4}{|l|}{ BMI categories } \\
\hline Underweight & 1.58 & $1.29-1.93$ & $<0.0001$ \\
\hline Normal weight & Reference & & \\
\hline Overweight & 0.80 & $0.73-0.87$ & $<0.0001$ \\
\hline Obese & 0.84 & $0.76-0.93$ & 0.001 \\
\hline \multicolumn{4}{|l|}{ Ever hookah smoker } \\
\hline Yes & 0.67 & $0.53-0.83$ & $<0.0001$ \\
\hline No & Reference & & \\
\hline \multicolumn{4}{|l|}{ Sleeping duration } \\
\hline Enough & Reference & & \\
\hline Not enough & 1.04 & $0.96-1.12$ & 0.338 \\
\hline Excessive & 1.19 & $1.06-1.35$ & 0.004 \\
\hline \multicolumn{4}{|l|}{ Medical characteristics } \\
\hline \multicolumn{4}{|l|}{ Metabolic syndrome } \\
\hline Yes & 0.87 & $0.80-0.95$ & 0.002 \\
\hline No & Reference & & \\
\hline \multicolumn{4}{|l|}{ CKD } \\
\hline Yes & 1.27 & $(1.12-1.44)$ & $<0.0001$ \\
\hline Non-CKD / Unknown & Reference & & \\
\hline
\end{tabular}

Abbreviations: $\mathrm{Cl}$ confidence interval, $O R$ odds ration, $B M I$ body mass index Notes: ${ }^{a}$, the ORs and $95 \% \mathrm{Cls}$ were generated from the logistic regression analysis. Significance level was at $p$-value $<0.05$

b , adjusted for gender, age groups, BMI categories, occupation, area of residence, hookah smoking, presence of CKD, presence of metabolic syndrome, night sleep duration, marital status, and ethnicity. (Nagelkerke pseudo- $R^{2}=0.074$ and Hosmer-Lemeshow $p$-value $=0.107$ ) belonging to the underweight category of BMI, being unemployed or retired, and living in urban areas were major determinants of anemia prevalence in our study according to multivariable analysis. These results are mostly in agreement with findings obtained from previous investigations. The prevalence of anemia was clearly higher among women totally (OR: 3.17 ). This is consistent with numerous studies, [18-20, 23, 25] and may be simply explained by biological vulnerability of the inevitable iron loss during menstruation and pregnancy in the reproductive age as well as dietary inadequacy. Regarding age, it is important to note that there were differences between the genders. Among men, there was a steady increase in the prevalence of anemia with advancing age. On the other hand, women particularly had a higher prevalence of anemia in age group of 35-49 years, and then experienced a downward trend. Aging process, inflammation, menopause, chronic diseases, and reduction in testosterone production, all may explain these observed differences. Next factor is nutrition and economic status which work synergically toward anemia. As such, we observed that low BMIs and undernourished individuals have an inverse relationship with anemia. Although low BMI may not necessarily imply poorer micronutrient intake, they are more likely to have other concomitant comorbidities and hence, poorer nutrition. Unlike most earlier studies, $[8,26]$ the two variables of lower educational levels and wealth index quantiles did not significantly influence the anemia prevalence in our model, however, the differences were meaningful in univariate analysis. This may be explained by the improved economic status of the region, and thereby, improved nutrition conditions, lower infection rates, better health-related access, and other favorable living conditions. Housewives were the most prevalent form of occupation among anemic population. The gender-specific variation of the sample composition could have affected this outcome. After adjustment, the respective odds were strongly lowered, but the effect of being unemployed or retired remained pretty much the same on the prevalence of anemia. These observations are repeated in a cross-sectional study among apparently healthy residents in Ethiopia [26]. Unlike most other studies, [26-28] inhabitants of urban regions in our study tended to be more affected by anemia. Similar associations with geographic location have been found in Maldives and Timor-Leste [28].

In addition to factors described above, our study demonstrated a minor but significant positive association between anemia status and suffering from CKD, night sleep duration, and marital status, as well as a negative association between anemia and factors including hookah smoking and presence of metabolic syndrome. 
As expected, participants with CKD were more likely to suffer from anemia, as anemia is a well-known complication of CKD, mainly due to absolute or relative erythropoietin deficiency [29]. Recently, few epidemiological studies have observed an association between either a long or a short sleep duration and anemia prevalence, [30-32] i.e. anemia is less prevalent in individuals who sleep between 7 and $9 \mathrm{~h}$ per night. In the present study, we found also that a long sleep duration independently predicts an increased prevalence of anemia. However, it is not possible to exactly determine the causality based on this cross-sectional data and further comprehensive longitudinal studies are needed. Furthermore, this association may be more likely because of other unmeasured confounding factors like poor sleep quality. To date, no definite underlying mechanism exists in this regard. Inflammation is one of the proposed biological pathways. It has been observed that the level of inflammatory markers including sensitivity C-reactive protein is higher in those with extreme sleep duration and also in anemic individuals [30, 31, 33]. Also, both disturbed sleep duration and anemia can cause serious health issues, like stroke, coronary heart disease and mortality events [34]. Therefore, it would be beneficial if our physicians are aware of this association and consider sleep problems in anemia treatment as a modifiable risk factor. In this study, the odds of having anemia in married individuals, after being adjusted, remained slightly higher when compared with their counterparts. However, Rwanda and south and southeast Asian countries demonstrated higher prevalence of anemia in widowed or divorced women of reproductive age, but still not the never married women [28, 35]. It could probably be hypothesized that women are susceptible to more menstruation, pregnancy and birthrelated complications, resulting in recurrent blood loss, and men are predisposed to economic deprivation, poverty, and malnutrition less time spent on health services, as they are the main breadwinners of their family [36]. It is also important for policy makers to mention that the majority of women marry during adolescence for traditional reasons in Khuzestan, and therefore, are exposed to its complications earlier [37].

Hookah is a classical style of tobacco smoking, originating from the middle east. Here we also observed that hookah smokers were less likely to have anemia. Hookah has already been recognized as a stimulant of HGB production due to induced hypoxemia, [38] and the lower prevalence of anemia among hookah smokers in our study may be attributed to this reason. This result is also consistent with a study conducted in Taif city in Saudi Arabia, which was found that shisha or cigarette smoking cause increased HGB levels and secondary polycythemia [39]. Although the cigarette smoking contributed to the same correlation in univariate analysis, it was not found significant in multivariate model. We should know that in a shisha session (which usually takes $20-80 \mathrm{~min}$ ), people inhale the same amount of over 100 cigarettes smoke and potentially exposes the smoker to more smoke over time [40]. Given a somehow similar mechanism to overweight or obesity, the presence of metabolic syndrome in a subject is another negative predictor of anemia prevalence. Other studies have also reported alterations in hematological parameters with a trend towards higher HGB concentrations in subjects with metabolic syndrome [41, 42]. And finally regarding ethnicity, we have to point out that there was no significant difference between Fars and Arabs or Bakhtiari in terms of anemia prevalence, who consist about $90 \%$ of our study population. However, a minor negative association was observed between anemia and being from minor ethnic groups (Lur, Turk, and Kurd). This may be of interest since Arabs are somehow genetically different from other Iranian ethnic groups compared to each other and Khuzestan province houses the largest population of Iranian Arabs [43].

\section{Strengths and limitations}

The strength of this report comes from the use of a large population-based multi-ethnic sample size covering 29,550 adult men and non-pregnant women from all counties of the Khuzestan province, which makes it very likely reflective of the current anemia status, with precise point estimates, in the general adult population of the region. The reliability and validity of the results were assured by the standardized quality control measures in data collection, management, and analysis. As a result, we could successfully propose some recommendations according to the identified associated factors of anemia for policy makers to implement measures to improve pertinent health status.

However, several limitations should be taken into account when discussing these results. Firstly, the KCHS data were collected in a one-time period with no followup to assess the impact of any interventions. Owing to the cross-sectional nature of the KCHS, no time precedence was recognized between most of the associated factors and anemia, thereby, the temporal causality pathway remained unclear. Secondly, the results of this report are not generalizable to younger or older age groups than our included age category of 20-65 years. Thirdly, the response rate in women was higher in comparison to men, However, this was adjusted by reporting genderspecific prevalence rates in data analysis. Fourthly, the majority parts of the data collection process in KCHS was questionnaire-based and relied on the respondents' memory, which unavoidably might have caused recall bias. Also, we acknowledge the presence of a few missing data, 
although they seem negligible. Fifth, despite several existing definitions and cut-off values of anemia, we utilized the one from WHO based on the HGB concentration alone. Finally, our study lacks certain important influential factors, as well as etiological factors, for further interpretation of the attributed risk of anemia. These include dietary patterns, iron indices, or vitamin levels, presence of infections, inherited HGB variants, underlying chronic diseases, and bleeding history. Thus, regarding the subtypes and probable causes for anemia, we could only speculate possibilities based on MCV and MCHC.

\section{Conclusions}

The results presented here provide for the first time an overview of anemia prevalence and its characterization in the men and non-pregnant women aged between 20-65 years in Khuzestan province, Iran. Taken together, the overall prevalence of anemia in this study population was of mild public health significance according to WHO classification and similar to other high-income countries. Furthermore, more than two-third of these cases had mild anemia. The high proportion of normochromic/microcytic, hypochromic/microcytic, and normochromic/normocytic anemias in our study may point towards the fact that the main causes of anemia are anemias of iron deficiency, chronic disease, and thalassemia. A comparably higher rates of anemia were observed amongst women, individuals aged 35-49 years, underweights, unemployed or retired subjects, and urban resident. To a minor degree, being 50-65 years of age, housewife, excessive night sleeper, CKD sufferer, and married were also related to anemia. Our epidemiological findings could provide reliable evidence for effective intervention strategies to prevent and control anemia by targeting the observed vulnerable population, particularly through paying adequate clinical attention in terms of iron status and underlying pathological conditions.

\begin{abstract}
Abbreviations
KCHS: Khuzestan comprehensive health study; HGB: Hemoglobin; WHO: World health organization; RBC: Red blood cell; GBD 2013: Global burden of diseases, injuries and risk factors 2013; YLD: Years lived with disability; NIMAD: National institute for medical research development; IBTO: Iranian blood transfer organization; DDRI: Digestive diseases research institute; TUMS: Tehran university of medical sciences; MCHC: Mean corpuscular hemoglobin concentration; MCV: Mean corpuscular volume; OR: Odds ratio; CKD: Chronic kidney disease; BMI: Body mass index; ELSA: English longitudinal study of ageing.
\end{abstract}

\section{Supplementary Information}

The online version contains supplementary material available at https://doi. org/10.1186/s12889-022-12512-6.

Additional file 1.

Additional file 2 .
Acknowledgements

Not applicable

\section{Authors' contributions}

EA and YP contributed equally to this work as first authors. HP and AASH contributed equally to this work as corresponding authors. EA analyzed and interpreted the data. EA and YP reviewed the literature, and wrote the paper. ZM and AASH supervised the project and reviewed the article before submission. $\mathrm{BCH}$ and $\mathrm{MZ}$ took part in performing the analysis. ZR, AM, FA, LD and SHA supervised the data gathering and reviewed the article before submission. HP designed, supervised and coordinated the program. All authors read and approved the final manuscript.

\section{Funding}

This project was funded by the National Institute for Medical Research Development (NIMAD) (grant number: 940406). This funding source had no role in the design of this study and collection, analysis, and interpretation of data and in writing the manuscript.

\section{Availability of data and materials}

The datasets used and analyzed during the current study are available from the corresponding author on reasonable request.

\section{Declarations}

\section{Ethics approval and consent to participate}

The KCHS protocol was approved by the ethics committees of the National Institute for Medical Research Development (NIMAD) (IR.NIMAD.REC.1394.002), and was conducted in accordance with the Declaration of Helsinki. A written informed consent was obtained from all participants initially. If the participant was illiterate, the legally authorized representative or the guardians provided written informed consent.

\section{Consent for publication}

Not applicable

\section{Competing interests}

The authors declare that they have no competing interests.

\section{Author details}

${ }^{1}$ Liver and Pancreatobiliary Diseases Research Center, Digestive Disease Research Institute, Tehran University of Medical Sciences, Shariati Hospital, N. Kargar St., 14117 Tehran, Iran. ${ }^{2}$ School of Medicine, Dezful University of Medical Sciences, Dezful, Iran. ${ }^{3}$ Alimentary Tract Research Center, Imam Khomeini Hospital Clinical Research Development Unit, School of Medicine, Ahvaz Jundishapur University of Medical Sciences, Ahvaz, Iran. ${ }^{4}$ Behbahan Faculty of Medical Sciences, Behbahan, Iran. ${ }^{5}$ Shoshtar Faculty of Medical Sciences, Shoshtar, Iran. ${ }^{6}$ Abadan Faculty of Medical Sciences, Abadan, Iran. ${ }^{7}$ Department of Epidemiology, School of Public Health, Iran University of Medical Sciences, Tehran, Iran. ${ }^{8}$ Digestive Diseases Research Institute, Tehran University of Medical Sciences, Tehran, Iran. ${ }^{9}$ Alimentary Tract Research Center, Clinical Sciences Research Institute, Department of Biostatistics and Epidemiology, School of Public Health, Ahvaz Jundishapur University of Medical Sciences, Ahvaz, Iran. ${ }^{10}$ Alimentary Tract Research Center, Imam Khomeini Hospital Clinical Research Development Unit, Department of Biostatistics and Epidemiology, School of Public Health, Ahvaz Jundishapur University of Medical Sciences, Ahvaz, Iran. ${ }^{11}$ Gastroenterology Department, Imam Khomeini Hospital, Azadegan Ave, Ahvaz, Iran.

Received: 17 December 2020 Accepted: 5 January 2022 Published online: 25 January 2022

\section{References}

1. WHO. Haemoglobin concentrations for the diagnosis of anaemia and assessment of severity. Vitamin and Mineral Nutrition Information System. Geneva, World Health Organization, 2011 (WHO/NMH/NHD/MNM/11.1) (http://www.who.int/vmnis/indicators/haemoglobin.pdf, Accessed 10 October 2020. 
2. Milman N. Anemia_still a major health problem in many parts of the world! Ann Hematol. 2011;90(4):369-77.

3. Kassebaum NJ, Jasrasaria R, Naghavi M, Wulf SK, Johns N, Lozano R, et al. A systematic analysis of global anemia burden from 1990 to 2010. Blood. 2014;123(5):615-24.

4. Kassebaum NJ. The global burden of anemia. Hematology/Oncology Clinics. 2016;30(2):247-308.

5. Ershler WB, Chen K, Reyes EB, Dubois R. Economic burden of patients with anemia in selected diseases. Value in Health. 2005:8(6):629-38.

6. De Benoist B, Cogswell M, Egli I, McLean E. Worldwide prevalence of anaemia 1993-2005; WHO Global Database of anaemia. 2008.

7. WHO. Iran (Islamic Rrepublic of). The database on Anaemia includes data by country on prevalence of anaemia and mean haemoglobin concentration. Vitamin and Mineral Nutrition Information System. Geneva, World Health Organization, 2007. (http://www.who.int/vmnis/anaemia/data/ database/countries/irn_ida.pdf, Accessed 22 October 2020.

8. Balarajan Y, Ramakrishnan U, Özaltin E, Shankar AH, Subramanian S. Anaemia in low-income and middle-income countries. The lancet. 2011;378(9809):2123-35.

9. Stevens GA, Finucane MM, De-Regil LM, Paciorek CJ, Flaxman SR, Branca F, et al. Global, regional, and national trends in haemoglobin concentration and prevalence of total and severe anaemia in children and pregnant and non-pregnant women for 1995-2011: a systematic analysis of population-representative data. Lancet Glob Health. 2013;1(1):e16-25.

10. Turgeon ML. Clinical hematology: theory and procedures. 4th Ed: Lippincott Williams \& Wilkins; 2005. p. 113. https://books.google.com/books? id $=$ cHAjsUgegpQC\&printsec $=$ frontcover\&source=gbs_ge_summary_r\& $\mathrm{cad}=0 \# \mathrm{v}=$ onepage $\& \mathrm{q} \& \mathrm{f}=\mathrm{false}$

11. Martinsson A, Andersson C, Andell P, Koul S, Engström G, Smith JG. Anemia in the general population: prevalence, clinical correlates and prognostic impact. Eur J Epidemiol. 2014;29(7):489-98.

12. Haas JD, Brownlie T IV. Iron deficiency and reduced work capacity: a critical review of the research to determine a causal relationship. J Nutr. 2001;131(2):676S-S690.

13. Bailey RA, Reardon G, Wasserman MR, McKenzie RS, Hord RS. Association of anemia with worsened activities of daily living and health-related quality of life scores derived from the minimum data set in long-term care residents. Health Qual Life Outcomes. 2012;10(1):129.

14. Nazari M, Mohammadnejad E, Dalvand S, Gheshlagh RG. Prevalence of iron deficiency anemia in Iranian children under 6 years of age: a systematic review and meta-analysis. Journal of blood medicine. 2019;10:111.

15. Akbari M, Moosazadeh M, Tabrizi R, Khatibi SR, Khodadost M, Heydari ST, et al. Estimation of iron deficiency anemia in Iranian children and adolescents: a systematic review and meta-analysis. Hematology. 2017;22(4):231-9.

16. Barooti E, Rezazadehkermani M, Sadeghirad B, Motaghipisheh S, Tayeri $\mathrm{S}$, Arabi $\mathrm{M}$, et al. Prevalence of iron deficiency anemia among Iranian pregnant women; a systematic review and meta-analysis. Journal of reproduction \& infertility. 2010;11(1):17.

17. Cheraghian B, Sharafkhah M, Mohammadi Z, Hariri S, Rahimi Z, Danehchin $\mathrm{L}$, et al. The Khuzestan Comprehensive Health Study (KCHS): methodology and profile of participants. Arch Iran Med. 2020;23(10):653-7.

18. Pouraram H, Djazayery A, Mohammad K, Parsaeian M, Abdollahi Z, Motlagh $\mathrm{AD}$, et al. Second national integrated micronutrient survey in Iran: Study design and preliminary findings. Arch Iran Med. 2018;21(4):137-44.

19. EFTEKHARZADEH MI, HEDAYATI MMR, Fathimoghadam F, Bidkhori HR, Shamsian SK. Anemia as a public health issue in Mashhad, Iran: evidence from the first population-based study. 2015.

20. Kolahi S, Farzin H, Khoshbaten M. Hypochromic microcytic anemia in Northwestern of Tabriz. Iran Eur J Gen Med. 2008:5(3):178-80.

21. Walker HK, Hall WD, Hurst JW. Clinical Methods: The History, Physical, and Laboratory Examinations. 3rd Ed. Chapter 152: Red Cell Indices by P. Ravi Sarma. Boston: Butterworths; 1990. ISBN-10: 0-409-90077-X. https://www. ncbi.nlm.nih.gov/books/NBK260/.

22. Jablonka A, Wetzke M, Sogkas G, Dopfer C, Schmidt RE, Behrens GM, et al. Prevalence and types of Anemia in a large refugee cohort in Western Europe in 2015. J Immigr Minor Health. 2018:20(6):1332-8.

23 Machado ÍE, Malta DC, Bacal NS, Rosenfeld LGM. Prevalence of anemia in Brazilian adults and elderly. Rev Bras Epidemiol. 2019;22(SUPL. 2):E190008.

24. Sgnaolin V, Engroff P, Ely LS, Schneider RH, Schwanke CHA, Gomes I, et al. Hematological parameters and prevalence of anemia among free-living elderly in south Brazil. Rev Bras Hematol Hemoter. 2013;35(2):115-8.
25. Bikbov MM, Kazakbaeva GM, Zainullin RM, Salavatova VF, Gilmanshin TR, Yakupova DF, et al. Prevalence and associated factors of anemia in a Russian population: the Ural eye and medical study. BMC Public Health. 2019;19(1):762.

26. Tesfaye TS, Tessema F, Jarso H. Prevalence of anemia and associated factors among "apparently healthy" urban and rural residents in Ethiopia: A Comparative Cross-Sectional Study. J Blood Med. 2020;11:89.

27. Adamu AL, Crampin A, Kayuni N, Amberbir A, Koole O, Phiri A, et al. Prevalence and risk factors for anemia severity and type in Malawian men and women: urban and rural differences. Popul Health Metrics. 2017;15(1):12.

28. Sunuwar DR, Singh DR, Chaudhary NK, Pradhan PMS, Rai P, Tiwari K. Prevalence and factors associated with anemia among women of reproductive age in seven South and Southeast Asian countries: Evidence from nationally representative surveys. PloS One. 2020;15(8):e0236449.

29. McFarlane SI, Chen S-C, Whaley-Connell AT, Sowers JR, Vassalotti JA, Salifu $\mathrm{MO}$, et al. Prevalence and associations of anemia of CKD: Kidney early evaluation program (KEEP) and national health and nutrition examination survey (NHANES) 1999-2004. Am J Kidney Dis. 2008;51(4):S46-55.

30. Jackowska M, Kumari M, Steptoe A. Sleep and biomarkers in the English Longitudinal Study of Ageing: associations with C-reactive protein, fibrinogen, dehydroepiandrosterone sulfate and hemoglobin. Psychoneuroendocrinology. 2013;38(9):1484-93.

31. Liu X, Song Q, Hu W, Han X, Gan J, Zheng X, et al. Night sleep duration and risk of incident anemia in a chinese population: a prospective cohort study. Sci Rep. 2018;8(1):1-7.

32 Chun MY, Kim JH, Kang JS. Relationship between Self-Reported Sleep Duration and Risk of Anemia: Data from the Korea National Health and Nutrition Examination Survey 2016-2017. Int J Environ Res Public Health. 2021;18(9):4721.

33. Grandner MA, Buxton OM, Jackson N, Sands-Lincoln M, Pandey A, JeanLouis G. Extreme sleep durations and increased C-reactive protein: effects of sex and ethnoracial group. Sleep. 2013;36(5):769-79.

34. Aurora RN, Kim JS, Crainiceanu C, O'Hearn D, Punjabi NM. Habitual sleep duration and all-cause mortality in a general community sample. Sleep. 2016:39(11):1903-9.

35. Hakizimana D, Nisingizwe MP, Logan J, Wong R. Identifying risk factors of anemia among women of reproductive age in Rwanda-a cross-sectional study using secondary data from the Rwanda demographic and health survey 2014/2015. BMC Public Health. 2019;19(1):1662.

36. Arpey NC, Gaglioti AH, Rosenbaum ME. How socioeconomic status affects patient perceptions of health care: a qualitative study. J Prim Care Community Health. 2017:8(3):169-75.

37. Tiruneh FN, Tenagashaw MW, Asres DT, Cherie HA. Associations of early marriage and early childbearing with anemia among adolescent girls in Ethiopia: a multilevel analysis of nationwide survey. Archives of Public Health. 2021;79(1):1-10.

38. Verma R, Patel C. Effect of smoking on Haematological parameters in Human Beings. Journal of Cell \& Tissue Research. 2005;5:337-40.

39. AlQahtany FS, Algahtani FH, Alshebly MM, Madkhaly FM, Ghandour MK, Almalki JH, et al. Association between cigarette \& shisha smoking and the severity of polycythemia: A cross sectional study. Saudi J Biol Sci. 2020;27(1):460-4.

40. Organization WH, Regulation WSGoTP. Advisory note: waterpipe tobacco smoking: health effects, research needs and recommended actions by regulators. 2015.

41. Laudisio A, Bandinelli S, Gemma A, Ferrucci L, Antonelli IR. Metabolic syndrome and hemoglobin levels in elderly adults: the Invecchiare in Chianti Study. J Am Geriatr Soc. 2013;61 (6):963-8.

42. Hämäläinen P, Saltevo J, Kautiainen H, Mäntyselkä P, Vanhala M. Erythropoietin, ferritin, haptoglobin, hemoglobin and transferrin receptor in metabolic syndrome: a case control study. Cardiovasc Diabetol. 2012;11(1):116

43. Nasidze I, Quinque D, Rahmani M, Alemohamad SA, Stoneking M. Close genetic relationship between Semitic-speaking and Indo-Europeanspeaking groups in Iran. Ann Hum Genet. 2008;72(2):241-52.

\section{Publisher's Note}

Springer Nature remains neutral with regard to jurisdictional claims in published maps and institutional affiliations. 